\title{
De-efferentation and De-afferentation in Fulminant Polyneuropathy: Lessons from the Isolated Brain
}

Can. J. Neurol. Sci. 2003; 30: 305-306

Friedman and colleagues ${ }^{1}$ present two cases of the axonal form of Guillain-Barré syndrome) / acute motor and sensory axonal neuropathy) in which the features closely mimicked brain death: cranial nerve areflexia (including both internal and external ophthalmoplegia) and lack of motor response or any movement. The patients were not tested for apnea, but this would likely also have been present, in that their weakness was profound and they did not trigger the ventilator.

The reports are instructive for several reasons:

1. The diagnosis of brain death should never be made without establishing a clear etiology. ${ }^{2}$ Furthermore, the etiology should be something capable of causing neuronal death. ${ }^{2}$

2. The apnea test for brain death should only be done when all of the preceding criteria for brain death are met, including establishing the etiology. ${ }^{2}$

3. Brain death has a number of mimics, including hypothermia, drug intoxication and neuromuscular paralysis; fulminant polyneuropathy should be added to that list.

4. Electrophysiological testing is valuable in the investigation of unresponsive states in the intensive care unit (ICU). Such tests go beyond the clinical evaluation and are invaluable in the assessment of the central and peripheral nervous system functions. Many clinicians seem unaware of this role and are more fixated on tests of structure (neuroimaging), which would have been useless in the cases presented in this article. Some features made the diagnosis of a polyneuropathy clinically difficult, especially in the first case. Alteration of consciousness and extensor plantar responses suggest central nervous system (CNS) involvement. The persistent cerebrospinal fluid pleocytosis in the first case is also atypical. Some cases of polyneuropathy may not be purely "peripheral", but may show CNS dysfunction or structural changes, possibly due to unrecognized-shared epitopes between the central and peripheral nervous systems. ${ }^{3-5}$ Although the CT scan was negative, MRI scanning might have revealed white matter lesions. Other explanations for CNS involvement might include septic, metabolic or hypotensive encephalopathy. The main cause of the unresponsive state, however, was the profound peripheral neuropathy in the two cases and it seems unlikely that there was a major CNS component.

What becomes of the brain-mind when the CNS is deefferented and de-afferented in severe polyneuropathy? Both patients recalled little of their acute illnesses. Undoubtedly prolonged length of stay, sedation and septic complications contribute to the loss of memory for much of the time for previous ICU patients, but this is unlikely the only explanation. ${ }^{6-9}$ Sleepwake cycles are disturbed in patients in ICUs. ${ }^{10}$ With deafferentation, wake and sleep cycles would not be entrained by environment but would be free-running. ${ }^{11}$ However, if illumination (the patients likely would perceive light even through closed lids) was fairly constant, melatonin secretion and circadian rhythms are suppressed, for extended times. ${ }^{12}$ Hallucinations often accompany sensory deprivation and sleep disturbances. ${ }^{13}$ Could the patients have been amnestic for these or were they too embarrassed to mention them? In addition, the patients could have undergone extreme psychological stress; their amnesia may reflect a posttraumatic stress disorder. ${ }^{14,15}$ Indeed, we have found considerable emotional and social morbidity in survivors of sepsis who were in ICU. ${ }^{16}$ Increases in plasma cortisol, as would be expected in stress, suppress hippocampal activation. ${ }^{17,18}$ Altered limbic monoaminergic activity may also impair memory function, especially in males. ${ }^{19}$

The presence of theta or alpha activity on EEG does not necessarily imply theta or alpha pattern coma, ${ }^{20}$ unless these patterns were truly widespread and invariant, even with passive eye opening. Furthermore, it is unlikely that the patients were ever truly in coma. ${ }^{21}$ Unfortunately, only visual stimuli would provide valid testing for event-related (including cognitive) potentials, as other cranial and peripheral sensory nerves were almost certainly severely dysfunctional.

In addition to the practical aspects of the cases, it would be of interest in similar cases to study sleep, hormonal concentrations, EEGs and event-related potentials over at least several days. This should provide answers to the above questions and may lead to better management of patients with de-efferented and deafferented CNS, whose brains may still be awake and aware.

G. Bryan Young, London, Ontario

\section{REFERENCES}

1. Friedman Y, Lee L, Wherrett JR, Ashby P, Carpenter S. Simulation of brain death from fulminant de-efferentation. Can J Neurol Sci 2003; 30: 397-404.

2. Brain Death Task Force of the Canadian Neurocritical Care Group. Guidelines for the Diagnosis of Brain Death. Can J Neurol Sci 1999;26:64-66.

3. Thomas PK, Valentine A, Youl BD. Chronic inflammatory polyneuropathy with multifocal CNS demyelination in an Afrid. J Neurol Neurosurg Psychiatry 1996;61:529-530.

4. Okumura A, Ushida H, Maruyama K, et al. Guillain-Barré syndrome associated with central nervous system lesions. Arch Dis Child 2002;86:304-306.

5. Best PV. Acute polyradiculoneuritis associated with demyelinated plaques in the central nervous system. Report of a case. Acta Neuropathol 1985;67:230-234.

6. Jones C, Griffiths RD, Humphris G. Disturbed memory and amnesia related to intensive care. Memory 2000;8:79-94.

7. Garcia Linzana F, Peres Bota D, De Cubber M, Vincent JL. Long term outcome in ICU patients: what about quality of life? Intensive Care Med 2003;29:1286-1293.

8. Capuzzo M, Pinamonti A, Cingolami E, et al. Analgesia, sedation and memory of intensive care. J Crit Care 2001;16:83-89. 
9. Rothnhausler HB, Ehrentraut S, Stoll C, Schelling G, Kapfhammer HP. The relationship between cognitive performance and employment and health status in long-term survivors of acute respiratory distress syndrome. Gen Hosp Psychiatry 2001;23:9096.

10. Cooper AB, Thornley KS, Young GB, et al. Sleep in critically ill patients requiring mechanical ventilation. Chest 2000;117:809818.

11. Boivin DB, James FO, Santo JB, Calyurt O, Chalk C. Non-24-hour sleep-wake cycle syndrome following a car accident. Neurology 2003;60:1841-1843.

12. Reiter RJ. Melatonin: clinical relevance. Best Pract Res Clin Endocrinol Metab 2003;17:273-285.

13. Manford M, Andermann F. Complex visual hallucinations. Clinical and neurobiological insights. Brain 1998;121:1819-1840.

14. Klein E, Caspi Y, Gil S. The relation between memory of a traumatic event and PTSD: evidence from studies of traumatic brain injury. Can J Psychiatry 2003;48:28-33.

15. Jones C, Griffiths RD, Humphris G, Skirrow PM. Memory, delusions, and the development of acute posttraumatic stress disorder-related symptoms after intensive care. Crit Care Med 2001;29:573-580.

16. Lazoski A, Young GB, Phillips R. Quality of life following severe septic illness. Crit Care Med, in press.

17. Erickson K, Drevets W, Schulkin J. Glucocorticoid regulation of diverse cognitive functions in normal and pathological emotional states. Neurosci Biobehav Rev 2003;27:233-246.

18. Schelling G. Effects of stress hormones on traumatic memory formation and the development of post-traumatic stress disorder in critically ill patients. Neurobiol Learn Mem 2002;78:596-609.

19. Bowman RE, Beck KD, Luine VN. Chronic stress effects on memory: sex differences in performance and monoaminergic activity. Hormon Behav 3003:43:48-59.

20. Young GB, Blume WT, Campbell VM, et al. Alpha, theta and alphatheta coma: a clinical outcome study using serial recordings. Electroencephalogr Clin Neurophysiol 1994;91:93-99.

21. Niedermeyer E. Alpha rhythms as physiological and abnormal phenomena. Int J Psychophysiol 1997;26:31-49. 